Peer Reviewed Paper openaccess

\title{
High-resolution mapping of upland swamp vegetation using an unmanned aerial vehicle- hyperspectral system
}

\author{
Bikram Pratap Banerjee, ${ }^{\text {a Simit Raval }}{ }^{\mathrm{b},{ }^{*}}$ and Patrick Joseph Cullen ${ }^{\mathrm{c}}$ \\ ${ }^{a}$ Australian Centre for Sustainable Mining Practices, School of Mining Engineering, University of New South Wales, Sydney, Australia, NSW 2052. \\ ORCID: https://orcid.org/0000-0002-5542-3751 \\ ${ }^{b}$ Australian Centre for Sustainable Mining Practices, School of Mining Engineering, University of New South Wales, Sydney, Australia, NSW 2052. \\ E-mail: simit@unsw.edu.au. ORCID: https://orcid.org/0000-0002-0421-0940 \\ 'School of Chemical Engineering, University of New South Wales, Sydney, Australia, NSW 2052. ORCID: https://orcid.org/0000-0001-7654-6171
}

\begin{abstract}
Mapping of vegetation species and communities in sensitive ecosystems is essential for identification and management of anthropogenic impacts. Unmanned aerial vehicle (UAV)-hyperspectral systems are among the latest technologies in remote sensing that hold a potential for obtaining unprecedented quality of remote sensing data for vegetation mapping and health status monitoring applications. In this study, high-resolution $(1-1.5 \mathrm{~cm})$ spectral imaging data (15 bands) from a tunable spectrometer is used to map five species of vegetation in a complex upland swamp environment. The overall accuracy of classification was found to be $88.9 \%$ with a kappa coefficient of 0.83 . Three classes (bare earth, sedgeland grass and black sheoak) have achieved higher accuracy (above 78\%) and one class (bracken fern) has lower accuracy (58\%). UAV-hyperspectral technology is, therefore, an effective tool to identify and map sensitive swamp vegetation. The technology can be potentially applied to determine the health status of the species.
\end{abstract}

Keywords: UAV, hyperspectral, sensitive species, upland swamps

\section{Introduction}

Upland swamps are extensive areas of treeless heaths and sedgelands and are listed as highly sensitive ecosystems in New South Wales, Australia. ${ }^{1}$ The ecosystem is diverse and threatened. Precise and frequent mapping of the vegetation communities is essential for the sustainability of the environment. However, traditional aerial and satellite-based methods are limited to the delineation of the swamp boundaries. ${ }^{2}$ Identification of individual species and vegetation group is critical to characterise the vegetation communities in the swamps and is the first step towards monitoring of the changing health of the characteristic species under natural or anthropogenic stress. Previous studies, using ground-based spectroscopy for differentiation of vegetation species on wetland environment, revealed the spectral complexities of the process. ${ }^{3}$ Unmanned aerial vehicles (UAV) with optical and infrared cameras have been recently used, but were limited to mapping of the community boundaries ${ }^{4}$ and detection of a single species (Gleichenia dicarpa) only. ${ }^{5}$ It was, therefore,

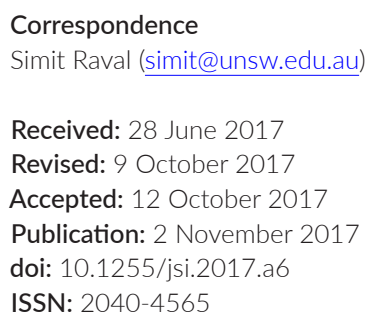

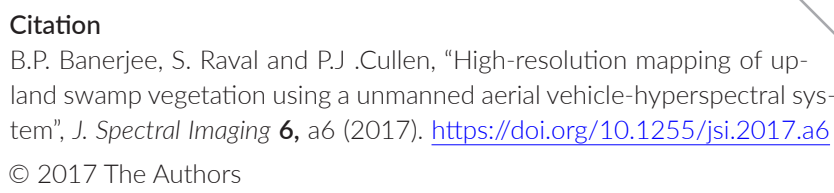
land swamp vegetation using a unmanned aerial vehicle-hyperspectral system", J. Spectral Imaging 6, a6 (2017). https://doi.org/10.1255/jsi.2017.a6 (c) 2017 The Authors

This licence permits you to use, share, copy and redistribute the paper in any medium or any format provided that a full citation to the original paper in this journal is given. 
deemed necessary to investigate the potential of a UAV-hyperspectral system to map the area at individual species level. In this study, we present preliminary results of the species differentiation and vegetation complexes over this spectrally diverse swamp environment. The high overall classification accuracy obtained in this study indicates benefits of high-resolution near-surface spectroscopy through UAVs for a heterogeneous ecosystem.

\section{Materials and methods \\ Test area and ground truth}

The study area is located near Wollongong, southwest to the city of Sydney, Australia (34 $21^{\prime} 24.0^{\prime \prime}$ S, $150^{\circ}$ $\left.51^{\prime} 51^{\prime \prime} \mathrm{E}\right)$. The area is comprised of shrub type vegetation thickets (Banksia and tea tree), and sedgelandheath complexes (Cyperoid, Restioid and sedgelands). ${ }^{1}$ To simplify the complexity in classification, we narrowed down to a set of five swamp species (Pteridium aqulinum, Allocasuarina littoralis, Empodisma minus, Lepidosperma limicola and Lepidosperma neesii) based on their abundance over the area and significance in terms of sensitivity (Figure 1).

A transect-based sampling design was adopted to collect ground truth points for the defined species using a handheld global positioning system (GPS). A transect is an imaginary line that spans the area of interest to select sample plots along this line to minimise sampling bias. In this case, the individual sampling transects were made to conform with the transects in which the UAV was operated.

\section{Remote sensing acquisition}

To scope the potential of spectroscopy in classification and to avoid loss of pixel purity due to low resolution, the UAV data were acquired at a low flying altitude of around $25 \mathrm{~m}$ in transects. Due to the high heterogeneity of the ecosystem together with the small and fragile canopy of a few target species, it was deemed necessary to acquire data at high spatial resolution. A high spatial resolution of $1-1.5 \mathrm{~cm}$ ground sampling distance (GSD) was achieved throughout the planned mission. Weather conditions were clear and illumination was sunny during the mission. Furthermore, the effect of shadow was minimal during the acquisition due to the sun angle at the time. For this mission, we used an octocopter-UAV assembled from off-the-self available parts (Walkera QR-X900). The flight control system (FCSRX705) is based on Ardupilot Mega (APM).

A programmable hyperspectral camera based on FabryPérot interferometer (FPI) ${ }^{6}$ technology was used with the UAV (Rikola, Senop Optronics, Finland). The integrated UAV-hyperspectral system is shown in Figure 2. The sensor provides spectral data cubes using a snapshotbased scanning mechanism; this enables high spatial registration between the pixels and bundle-block adjustment for photogrammetric applications. The sensor was used in un-binned mode $(1024 \times 1024)$ with a pixel size of $5.5 \mu \mathrm{m}$, focal length of $9 \mathrm{~mm}$ and field of view (FOV) of $36.5^{\circ}$. Furthermore, an onboard GPS receiver was used to acquire the start position of the hypercube acquisitions. A total of 15 wavelength bands were acquired over the operational wavelength range of $500-900 \mathrm{~nm}$. The exposure time was set at $10 \mathrm{~ms}$ to provide good image quality for the existing illumination condition. We used
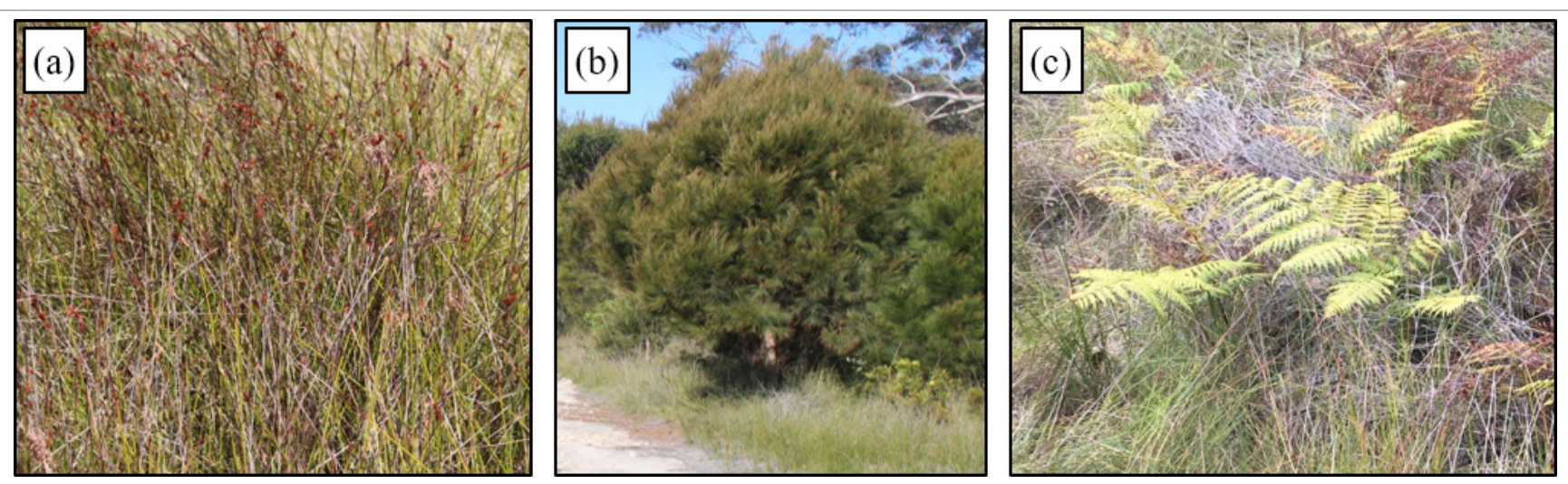

Figure 1(a). Sedgeland grass (Empodisma minus, Lepidosperma limicola, Lepidosperma neesii), (b) black sheoak (Allocasuarina littoralis) and (c) bracken fern (Pteridium aqulinum). 


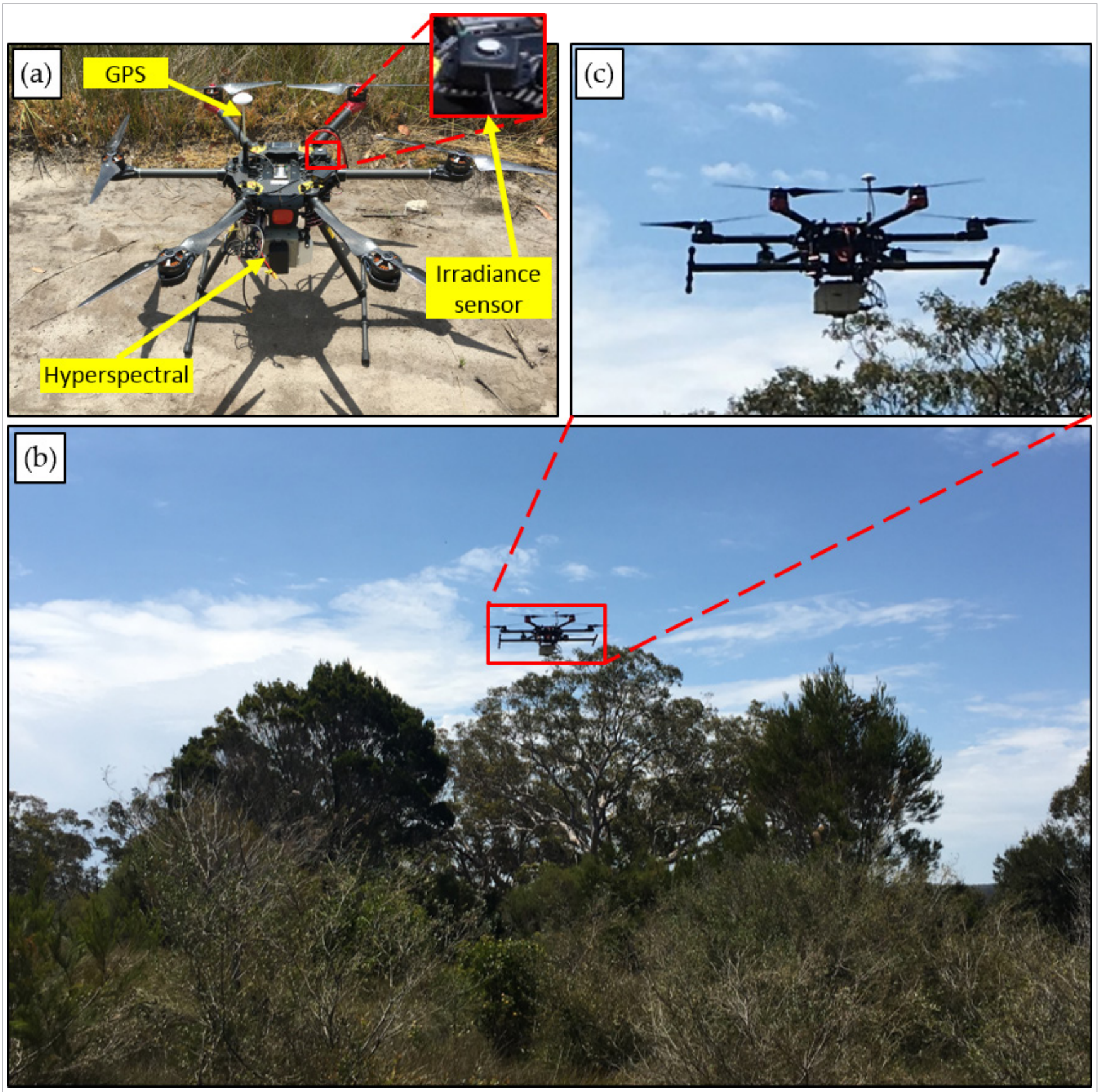

Figure 2. The integrated UAV-hyperspectral sensor system (a) on-ground, (b) during the survey and (c) enlarged view of system.

an indices-based methodology to tune the bands of the FPI sensor, i.e. the selected wavelengths are the primary input wavelengths for a set of 12 existing narrowband vegetation indices, listed in Table 1 . The selected wavelengths were 515.14, 531.50, 550.14, 570.18, 610.10, 670.31, 700.08, 710.12, 720.27, 740.40, 750.19, 762.02 , 780.33, 800.35 and $850.35 \mathrm{~nm}$ with respective full width at half maximum (FWHM) of 10.93, 10.29,
$9.58,9.63,11.88,11.76,9.87,9.78,9.61,9.58,9.58$, $9.37,9.58,10.62$ and $12.94 \mathrm{~nm}$.

\section{Processing workflow}

As a part of the data preprocessing routine, systematic corrections (spectral smile and dark signal) were first performed using laboratory calibration parameters. Ground-based reflectance signatures were used for 
Table 1. List of narrowband vegetation indices.

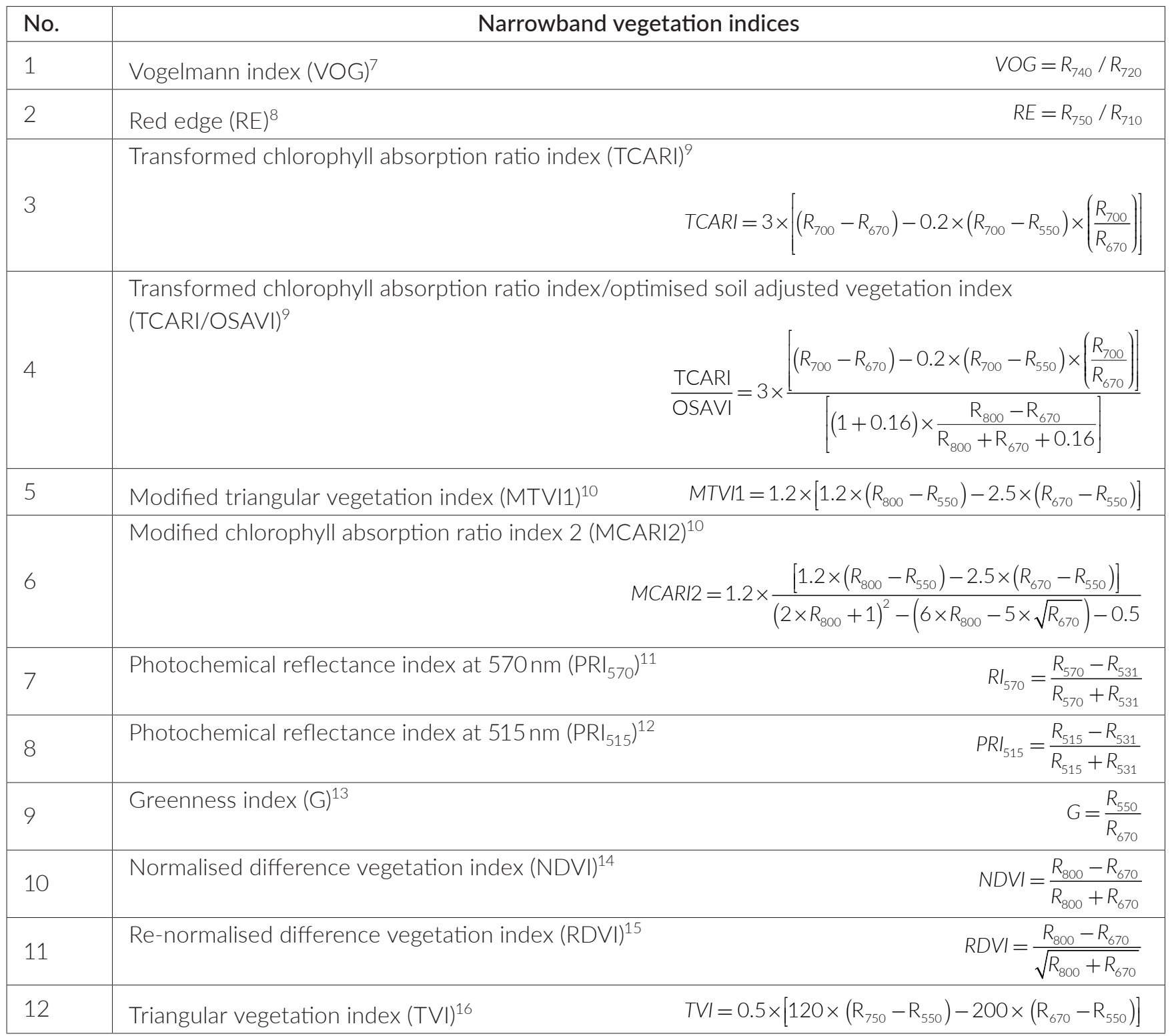

empirical line correction, ${ }^{17}$ to generate a reflectance equivalent for the acquired hypercubes. The snapshotbased scanning mechanism employed by the FPI produces spatial shifts between the band wise acquisitions due to the motion of the UAV. ${ }^{18}$ An "affine" geometric transformation was used by employing a spatial-featurebased keypoint matching technique to stabilise the shift between the band frames. The employed keypoint matching technique automatically identifies unique spatial features between a band-pair (two bands at a time in the sequence of all bands) and then geometrically transforms one of the bands to spatially overlap with the other. The coding was done through MATLAB and the method was evaluated through root mean square error (RMSE) and Pearson correlation coefficient (PCC). The individually stabilised reflectance images, along each transect, were then mosaicked together. In this mosaicking process, common spatial features between the adjacent bands in a transect were identified and used. All the pixels were adjusted to $1 \mathrm{~cm}$ GSD as an inherent resampling routine in the mosaicking process. Absolute geometric registration of the mosaicked datasets was performed using ground control points (GCP) collected from the survey and high-resolution optical airborne datasets (NearMap ${ }^{\mathrm{TM}}$ ) at $7.5 \mathrm{~cm}$ GSD. The resulting mosaicked dataset was classified using a super- 

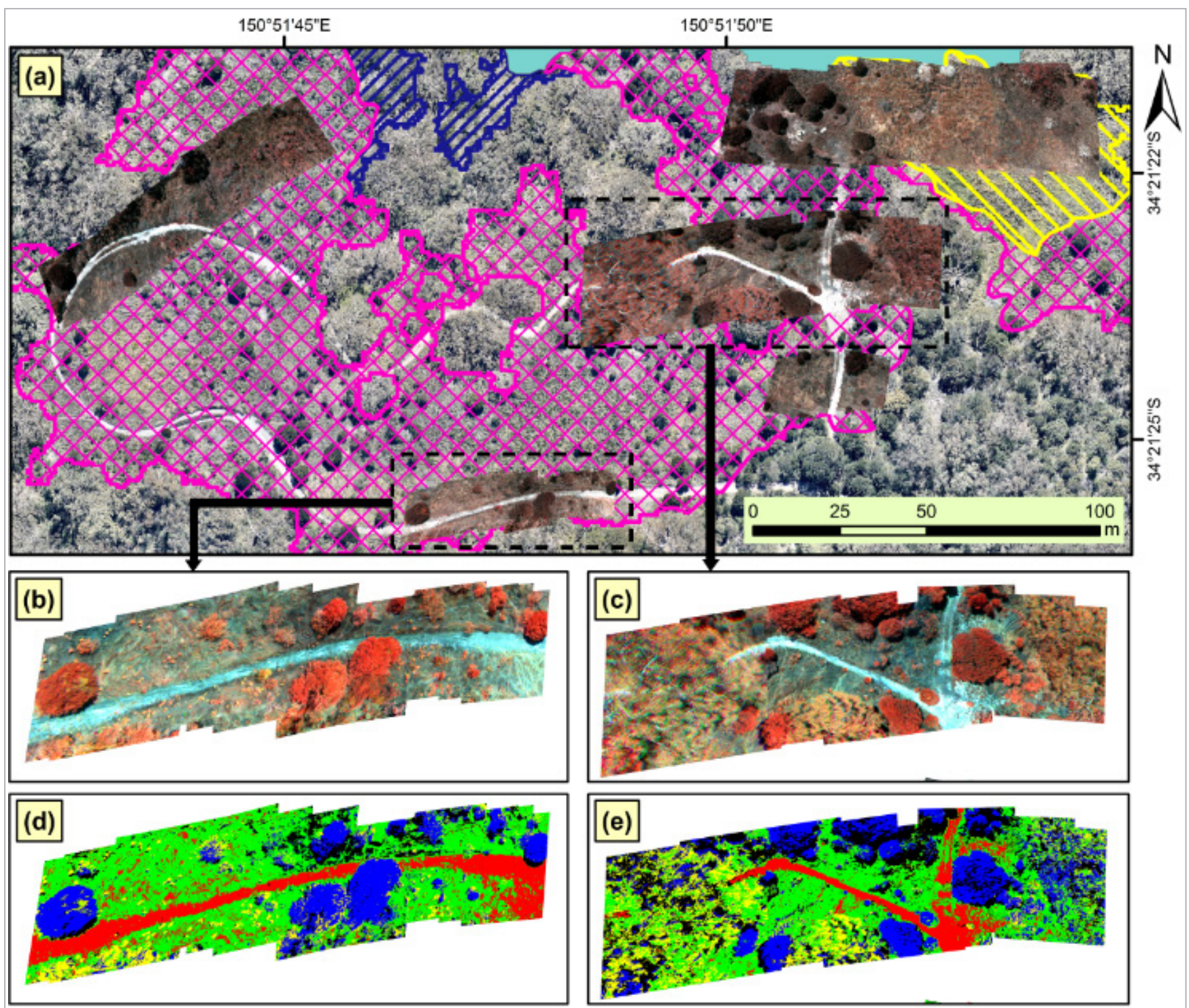

\section{Legend: Vegetation communities \\ ZD Banksia Thicket \\ Sedgeland-Heath Complex (Cyperoid Heath) \\ Sedgeland-Heath Complex (Restioid Heath) \\ $\triangle X$ Sedgeland-Heath Complex (Sedgeland)}

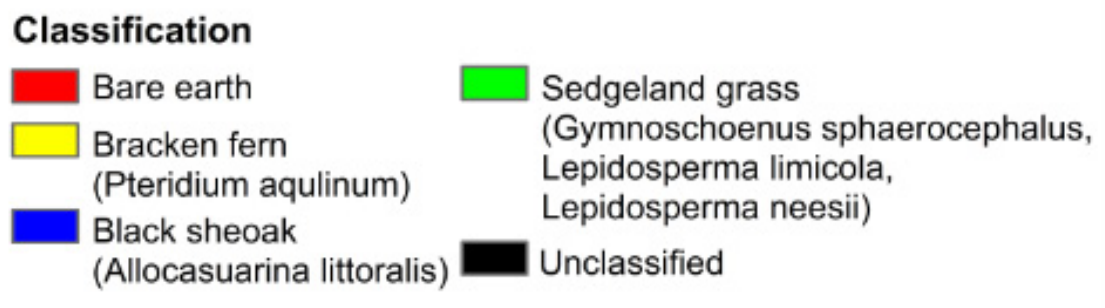

Figure 3(a). An overlay map of the acquired UAV-hyperspectral data over the swamp communities, (b) and (c) enlarged colour infrared composite $(850.35,670.31$ and $550.14 \mathrm{~nm})$ of two transects, and (d) and (e) classification outputs.

vised $n$-dimensional parallel-piped classifier $^{19}$ into three vegetation classes (Figure 1).

The training and the test sets were selected from the same image apart from the ground truth samples collected during the survey. The training polygons were collected using photo-interpretation of colour infrared composite (850.35, 670.31 and 550.14) of the mosaicked hyperspectral product for the classification. A total of 20 polygons (222,382 pixels) were selected for "bare earth", 22 polygons (498,031 pixels) were selected for "sedge- 
Table 2. Accuracy assessment for the classification.

\begin{tabular}{|l|c|c|c|c|}
\hline Class & $\begin{array}{c}\text { Producer } \\
\text { accuracy (\%) }\end{array}$ & $\begin{array}{c}\text { Omission error } \\
\text { (\%) }\end{array}$ & $\begin{array}{c}\text { User accuracy } \\
\text { (\%) }\end{array}$ & $\begin{array}{c}\text { Commission error } \\
\text { (\%) }\end{array}$ \\
\hline Bare earth (red) & 99.07 & 0.93 & 95.95 & 4.05 \\
\hline Sedgeland grass (green) & 78.83 & 21.17 & 97.83 & 2.17 \\
\hline Black sheoak (blue) & 85.29 & 14.71 & 99.98 & 0.02 \\
\hline Bracken fern (yellow) & 58.55 & 41.45 & 48.36 & 51.64 \\
\hline
\end{tabular}

land grass", 16 polygons (561,638 pixels) were selected for "black sheoak" and 18 polygons (6129 pixels) were selected for "bracken fern". The selection of the test polygons was based on the size and distribution of the target class. Furthermore, the set of training and test polygons were kept mutually separate in a 1:1 ratio for classification.

\section{Results and discussion}

Figure 3(a) shows the overlay of the data acquired through the UAV flight transects, Figure 3(b) and (c) show enlarged views of two transects, and Figure 3(d) and (e) show the classified outputs for the respective transects. The accuracy of the classification was evaluated with randomly selected test samples using a confusion matrix (Table 2). The overall classification accuracy was $88.9 \%$ with a kappa coefficient of 0.83 . The evaluation of the performance of other supervised and un-supervised classification techniques could be useful for future research over this challenging space.

Individual class accuracy was high for bare earth, sedgeland grass and black sheoak. However, the accuracy of the shrub type vegetation class (bracken fern) was significantly lower with higher commission and omission errors. This is likely to be due to the shrub type vegetation being largely present within the sedgeland grass community and the fractional canopy of the species introduced spectral mixing. It will be interesting to see the performance of objectbased classifiers on the acquired UAV-hyperspectral data for classification of given shrub-type vegetation species. In addition, to the classified pixels, several pixels were found to remain unclassified. This category largely belongs to the list of shrub-type species that were not classified in this exercise. Detection and classification of these unclassified species in the spectrally complex environment also is an identified future aspect of this research and could be useful for ecological management.

Overall high accuracy in detection of bare earth and swamp vegetation classes can be directly applied to estimate the percentage coverage of the vegetation in upland swamps.

\section{Conclusion}

The result of this preliminary study indicates that it is possible to detect and differentiate threatened swamp species using UAV-based spectroscopy at the required high spatial and spectral resolution. The results are useful to estimate the abundance and distribution of the species over the upland swamp. Furthermore, this can later be employed to identify health status at the species level. This in turn is crucial for understanding the condition of the swamp and identification of stress induced from anthropogenic sources.

\section{Acknowledgements}

This independent research was funded by the Australian Centre for Sustainable Mining Practices (ACSMP), School of Mining Engineering, UNSW, Australia, as a PhD scholarship for the first author. The authors acknowledge Office of Environment and Heritage, NSW, Australia, for providing swamp community layers. The authors thank Wollongong Coal, NSW, Australia, and Dr Katarina Mikac, School of Biological Sciences, University of Wollongong, NSW, Australia, for their support in carrying out the field work. 


\section{References}

1. The Native Vegetation of the Woronora, O'Hares and Metropolitan Catchments. NSW National Parks and Wildlife Service, Sydney, Australia (2003). http://www.environment.nsw.gov.au/surveys/ WoronoraAssessment.htm

2. R.B. Jenkins and P.S. Frazier, "High-resolution remote sensing of upland swamp boundaries and vegetation for baseline mapping and monitoring", Wetlands 30(3), 531-540 (2010). doi: https://doi. org/10.1007/s13157-010-0059-1

3. N. Torbick and B. Becker, "Evaluating principal components analysis for identifying optimal bands using wetland hyperspectral measurements from the Great Lakes, USA," Remote Sensing 1(3), 408-417 (2009). doi: https://doi.org/10.3390/rs1030408

4. A.M. Lechner, A. Fletchera, K. Johansen and P. Erskine, "Characterising upland swamps using object-based classification methods and hyper-spatial resolution imagery derived from an unmanned aerial vehicle", ISPRS Annals of the Photogrammetry, Remote Sensing and Spatial Information Sciences I-4, 101-106 (2012). doi: https://doi.org/10.5194/ isprsannals-1-4-101-2012

5. C. Strecha, A. Fletcher, A. Lechner, P. Erskine and F. Pascal, "Developing species specific vegetation maps using multi-spectral hyperspatial imagery from unmanned aerial vehicles", ISPRS Annals of the Photogrammetry, Remote Sensing and Spatial Information Sciences 3, 311-316 (2012). doi: https:// doi.org/10.5194/isprsannals-I-3-311-2012

6. H. Saari, V.-V. Aallos, A. Akujärvi, T. Antila, C. Holmlund, U. Kantojärvi, J. Mäkynen and J. Ollila, "Novel miniaturized hyperspectral sensor for UAV and space applications", Proc. SPIE

7474, Sensors, Systems, and Next-Generation Satellites XIII, 74741M (2009). doi: https://doi. org/10.1117/12.830284

7. J. Vogelmann, B. Rock and D. Moss, "Red edge spectral measurements from sugar maple leaves", Remote Sensing 14(8), 1563-1575 (1993). doi: https://doi. org/10.1080/01431169308953986

8. P.J. Zarco-Tejada, J.R. Miller, T.L. Noland, G.H. Mohammed and P.H. Sampson, "Scaling-up and model inversion methods with narrowband optical indices for chlorophyll content estimation in closed forest canopies with hyperspectral data", IEEE Transactions on Geoscience and Remote Sensing 39(7), 1491-1507 (2001). doi: https://doi. org/10.1109/36.934080
9. D. Haboudane, J.R. Miller, N. Tremblay, P.J. ZarcoTejada and L. Dextraze, "Integrated narrow-band vegetation indices for prediction of crop chlorophyll content for application to precision agriculture", Remote Sens. Environ. 81(2), 416-426 (2002). doi: https://doi.org/10.1016/S0034-4257(02)00018-4

10. D. Haboudane, J.R. Miller, E. Pattey, P.J. ZarcoTejada and I.B. Strachan, "Hyperspectral vegetation indices and novel algorithms for predicting green LAI of crop canopies: Modeling and validation in the context of precision agriculture", Remote Sens. Environ. 90(3), 337-352 (2004). doi: https://doi. org/10.1016/j.rse.2003.12.013

11. J.A. Gamon, J. Peñuelas and C.B. Field, "A narrow-waveband spectral index that tracks diurnal changes in photosynthetic efficiency", Remote Sens. Environ. 41(1), 35-44 (1992). doi: https://doi. org/1016/0034-4257(92)90059-S

12. R. Hernández-Clemente, R.M. Navarro-Cerrillo, L. Suárez, F. Morales and P.J. Zarco-Tejada, "Assessing structural effects on PRI for stress detection in conifer forests", Remote Sens. Environ. 115(9), 2360-2375 (2011). doi: https://doi.org/10.1016/j. rse.2011.04.036

13. P.J. Zarco-Tejada, A. Berjón, R. López-Lozano, J.R. Miller, P. Martín, V. Cachorro, M.R. González and A. de Frutos, "Assessing vineyard condition with hyperspectral indices: Leaf and canopy reflectance simulation in a row-structured discontinuous canopy", Remote Sens. Environ. 99(3), 271-287 (2005). doi: https://doi.org/10.1016/j.rse.2005.09.002

14. J. Rouse, R. Haas, J. Schell, D. Deering and J. Harlan, Monitoring the Vernal Advancement of Retrogradation of Natural Vegetation (Type III, Final Report). NASA/ GSFC, Greenbelt, MD, USA, p. 371 (1974).

15. J. Roujean and F. Breon, "Estimating PAR absorbed by vegetation from bidirectional reflectance measurements", Remote Sens. Environ. 51(3), 375-384 (1995). doi: https://doi.org/10.1016/00344257(94)00114-3

16. N.H. Broge and E. Leblanc, "Comparing prediction power and stability of broadband and hyperspectral vegetation indices for estimation of green leaf area index and canopy chlorophyll density", Remote Sens. Environ. 76(2), 156-172 (2001). doi: https://doi. org/10.1016/S0034-4257(00)00197-8

17. G.M. Smith and E.J. Milton, "The use of the empirical line method to calibrate remotely sensed data to reflectance", Int. J. Remote Sens. 
20(13), 2653-2662 (1999). doi: https://doi.

org/10.1080/014311699211994

18. E. Honkavaara, H. Saari, J. Kaivosoja, I. Pölönen,

T. Hakala, P. Litkey, J. Mäkynen and L. Pesonen,

"Processing and assessment of spectrometric, stereoscopic imagery collected using a lightweight UAV spectral camera for precision agriculture", Remote Sensing 5(10), 5006-5039 (2013). doi: https://doi. org/10.3390/rs5105006

19. J.A. Richards and J. Richards, Remote Sensing Digital Image Analysis. Springer (1999). doi: https://doi. org/10.1007/978-3-662-03978-6 